\title{
A Novel Methodology for Dynamic Weigh in Motion System for Railway Vehicles with Traction
}

\author{
Altan Onat, Bekir Tuna Kayaalp
}

\begin{abstract}
Loading conditions of railway vehicles both affect the vehicle and substructure directly. There are approaches to determine the load of a railway vehicle, the first one is to statically weigh the vehicle, the second approach is to place sensors along the track and dynamically weigh the vehicle at certain sections and the third one is to design special sensors that can be implemented on the vehicle. In this study, a model based indirect estimation methodology for normal load is proposed. This approach is based on interpreting angular velocities of wheels and translational velocity measurements of a vehicle to determine the normal load. A swarm intelligence based evolution of multiple models is proposed for estimation. In order to validate the approach, measurements taken from a tram wheel test stand with an independently rotating wheel are considered. The proposed approach is promising to be used as a dynamic weighing system and cost-efficient since only vehicle-based sensors are used. Furthermore, a continuous monitoring of the normal load is made possible with high accuracy since this methodology is neither limited to track-based sensors nor it requires special sensors and instrumented wheelsets.
\end{abstract}

Index Terms-Weigh-in-motion systems, railway vehicles, normal load estimation, multiple models, condition monitoring.

\section{INTRODUCTION}

C ONDITION and health monitoring based on low cost sensors and intelligent algorithms are becoming popular for all means of transport. Especially, such systems are useful to maintain safety and reliability.

In a fairly recent review [1], such on board condition and health monitoring systems are classified into two groups. The first group of systems is based on track-side sensors and the second group consider the data from sensors attached to the vehicle. Moreover, each group of systems are categorized as model and signal based. In model based methods, a mathematical model of the physical systems is created and by combining the results of this model and measurements with an intelligent algorithm, necessary inspection is made for the vehicle. Whereas signal based methods only consider data obtained from sensors and use it to interpret the situation. Main aspects, which are focused in the literature, are reported as wheel-rail health monitoring, suspension health monitoring, vehicle component health monitoring and running state monitoring, [1]. Wheel-rail condition monitoring covers a wide

A. Onat is with the Department of Electrical and Electronics Engineering, Eskisehir Technical University, Iki Eylul Campus, Eskisehir, 26555 TURKEY e-mail: altanonat@eskisehir.edu.tr.

B. T. Kayaalp is with Transport Means and Diagnostics, Faculty of Transportation Engineering, University of Pardubice, 53210 CZECHIA.

Manuscript received August 16, 2018.

Copyright (c) 2015 IEEE. Personal use of this material is permitted. However, permission to use this material for any other purposes must be obtained from the IEEE by sending a request to pubs-permissions@ieee.org. area including adhesion detection [2]-[5], rail defects detection [6]-[9], wheel condition monitoring [10]-[13]. Methodologies to observe suspension parameters are developed in [14]-[19].

Loading conditions directly affect the vehicle and substructure. Therefore, there are industrial and scientific methods for weigh in motion (i.e. WIM) systems and they are summarized in [20]. All of these methods are based on replacing sensors to the substructure elements like track, bridges, sleepers etc. and it depends on the stress, deformation, force measurements from the substructure. In [6], a methodology, which is based on putting a simple transducer to a hole drilled in the rail web, is proposed so that vertical and lateral forces exerted on the rail by train can be measured. A WIM system specific to railway bridges is presented in [21]. In [20], [22], a multibody model based methodology to estimate normal load and vehicle center of gravity is presented. However, this model based estimation algorithm depends on the measurements from force sensitive elements attached to the sleepers. Therefore, the algorithm in [20], [22] requires various measurement points along the track. It should be noted that track stiffness can be affected by environmental factors e.g. low temperature in winter or maintenance issues e.g. replacement of ballast, [21], and they are sensitive to the variables affected by the dynamic motion of a train such as track smoothness, wheel defects, truck hunting and skewing, and coupler effects, [23]. Therefore, their static and dynamic calibration must be carried out periodically. In [23], it is reported that the WIM systems used for North American railroads can achieve 98\% accuracy after static calibration.

Even though they are not mentioned as a WIM system, there are also systems which use special sensors or instrumented wheelsets to estimate contact forces to especially determine derailment coefficient (i.e. ratio of lateral contact force to vertical contact force). Thus, these forces can be considered to interpret the wheel load of a vehicle. Similar to the WIM systems reported in previous paragraph, contact force estimation systems use force sensitive elements (e.g. strain gages) and in this case, instead of replacing such elements to the track, bridge or sleepers, they are replaced to the wheel, [24], [25]. However, as stated in [26], the use of such systems is not suitable for commercial vehicles since tread braking of wheelsets equipped in this way is generally impossible due to the sensitivity of strain gages and similar elements to the generated heat. Moreover, application of such instrumentation to each wheelset is expensive. Other methods to estimate contact forces include design of special and specific sensors. In [26], [27], a magnetostrictive sensor is used to estimate vertical contact forces. Such sensor is used to interpret deflection 
between bogie and the wheelset to estimate load of a vehicle. Since the axle of the wheelset is drilled through for strain gage cabling, axle strength is insufficient for long-term use as stated in [27]. Therefore, instead of replacing force sensitive elements to the rotating parts, special sensors and apparatus are proposed in the literature, [26], [27]. However, it is obvious that the implementation and design of such specific sensing elements are costly. In a recent work [25], several studies reported as indirect methods to estimate contact forces. Firstly, such an indirect method is presented in [28] which is based on estimating vertical load by interpreting vertical acceleration measurements via inverse model. However, field tests shows that maximum correlation coefficient between measurements and estimated values is 0.73 which is not a promising result. Even though other studies [29], [30] are also reported as indirect method in [25], they are actually based on replacing strain gages to axle boxes or bogie. Therefore, approaches in [29], [30] are different from the indirect estimation concept presented here since the methodology given here proposes the use of velocity sensors which are already used for other purposes (speed determination and traction control) in railway vehicles, whereas replacing strain gages to non-rotating parts of the vehicle is called as indirect for the studies in [29], [30].

In this study, a model based novel approach is proposed which the normal load estimation is based on the indirect interpretation of wheel angular and vehicle translational velocities instead of measurements from the track or instrumented wheelsets. Therefore, neither various measurement points along the track nor special sensors attached to the wheelsets are required in this methodology. This approach assumes that the wheel angular and the vehicle translational velocities are measured. A high accuracy global positioning system (i.e. GPS) velocity sensor and high accuracy encoders are enough to determine such velocities. Additionally, the methodology proposed by the first author in [31], [32], is considered and estimation is based on the swarm of models which are evolving based on simple swarm intelligence. Models imply mathematical model of the system with different normal load estimates. Whenever a measurement is taken from the vehicle, the best model is selected for estimation based on the measurement so that the model, which represents vehicle dynamics most accurately, is chosen. The estimation methodology considers the fact that for different normal loads the dynamic response of the wheels to traction or track disturbances (simply excitation) are different. In this case, the creepage occurring between wheel and rail due to the traction changes according to the normal load and it is estimated based on the multiple models. Similarly, this approach is considered in [32] to estimate friction conditions indirectly.

Firstly, the general structure of the methodology is presented. Afterwards, the application of the methodology for the test system is reported. The test system is a tram wheel test stand which simulates the traction system of the trams which has independently rotating wheels and produced in Czechia. This test stand is a wheel on roller type roller-rig and similarly, it was previously used for testing a condition monitoring algorithm, [12].

The main advantage of the proposed approach is that it allows continuous monitoring of the normal load since it just depends on the vehicle based measurements. Therefore, there is no need to place sensors along the track in this methodology. However, in order to increase the accuracy of the estimation, this methodology can be combined with the approaches which use track based measurements so that the number of sensors which should be placed on the track can be decreased. Details of the application of the methodology for other types of railway vehicles, and advantages-disadvantages of the methodology are provided in the discussion section.

\section{General Structure of the Approach}

The general structure of the methodology is illustrated in Fig. 1.

Mathematical models of the system are started with proper initial conditions with respect to the vehicle. Whenever a measurement is taken from the vehicle, normal load estimates $\hat{N}_{i}$, where $i=1, \ldots, n$ and $n$ is the number of models, are updated with a swarm intelligence algorithm and the best model representing the vehicle dynamics is selected as the estimate. The selection of the best model is based on the measurement

$$
J=\left|s_{\text {model }_{j}}-s_{\text {measured }}\right|,
$$

where $J$ represents the cost function, $s$ is used for creepage, $s_{\text {model }_{j}}$ is the creepage value for $j^{\text {th }}$ model and $s_{\text {measured }}$ is the measured creepage value from the vehicle. The model, which provides minimum cost function $J_{\text {min }}$, is selected as the best model (i.e. estimate). The simplest explanation for the creepage is that it is the difference between circumferential velocity of a railway vehicle wheel and the translational velocity of the vehicle and it is expressed as

$$
s=\frac{v-\omega_{w} r_{w}}{\frac{1}{2}\left(v+\omega_{w} r_{w}\right)},
$$

where $\omega_{w}$ is the angular velocity of the wheel, $v$ is the translational velocity of the vehicle and $r_{w}$ is the rolling radius of the wheel. Creepage response due to the traction changes with respect to different normal loading conditions so that interpreting the data for the models and measurement makes estimation of the normal load possible. Therefore, in order to accurately estimate the normal load, the mathematical model, which represents the certain dynamics of the vehicle, is required.

In the following sections, the application of this methodology on a tram wheel test stand is presented.

\section{Mathematical Model of Tram Wheel Test Rig}

As previously indicated, this test stand is being used for validating recently developed condition monitoring methodologies. Information about the test stand can be found in [12], [32]-[34]. Schema of the test stand is given in Fig. 2.

This roller-rig is a wheel on roller type test stand. It is a full scale model of the trams with independently driven wheels which are produced in Czechia. Wheel is driven by a permanent magnet synchronous motor (i.e. PMSM) and the 


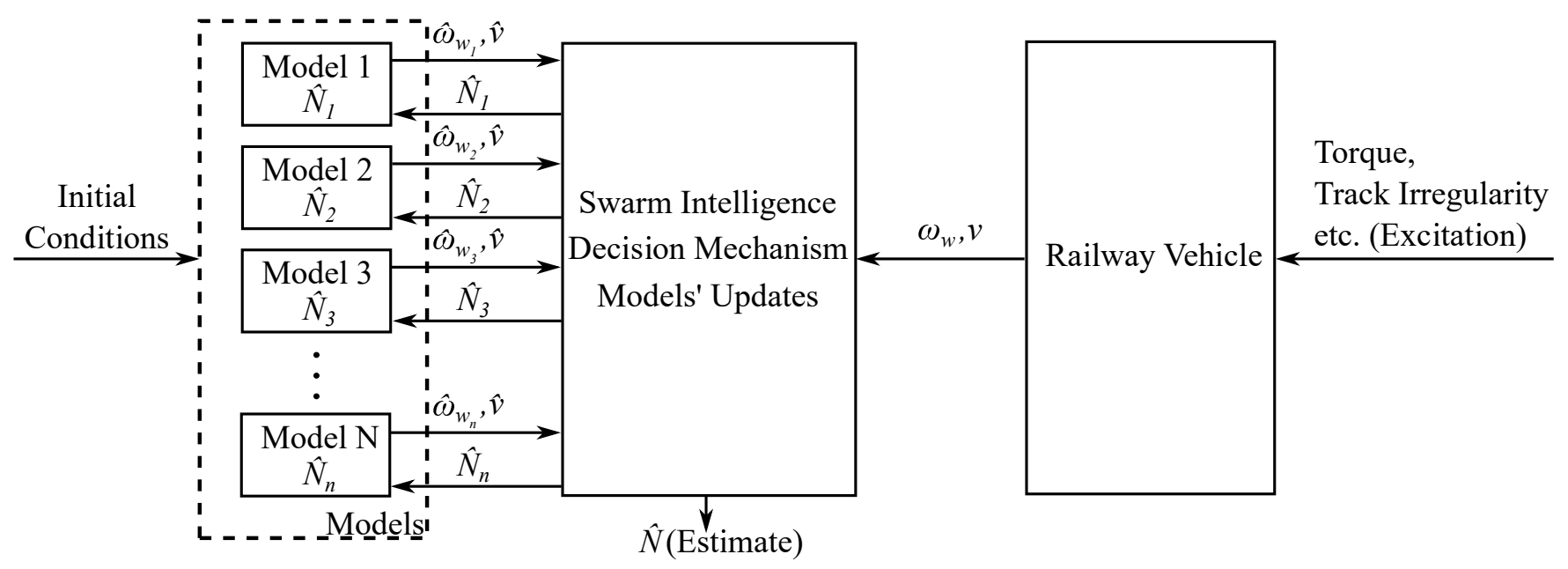

Fig. 1. General structure of the approach

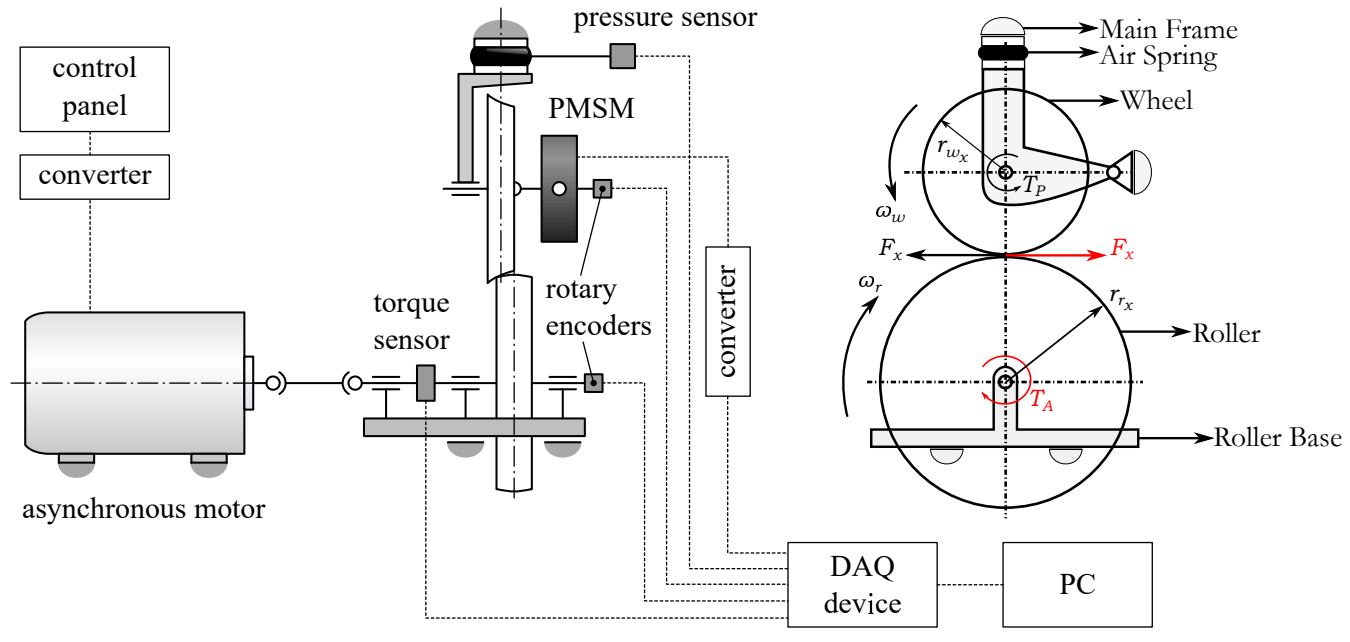

(a) Structure of the test rig

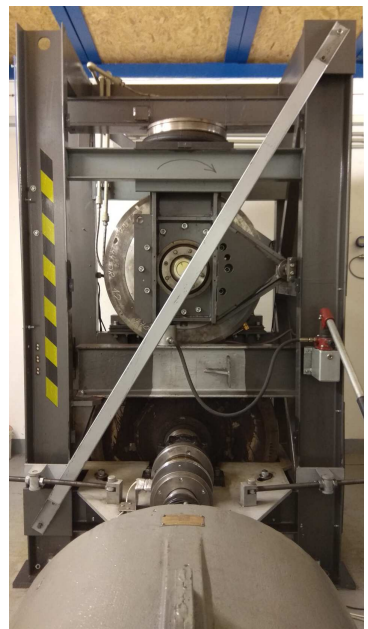

(b) A photo of the test stand

Fig. 2. Illustrations of the test rig

roller, which is manufactured from a wagon wheel, is driven by an asynchronous motor. Normal force on the wheel is exerted by a pressurized air spring and the normal force is measured by using the pressure transmitter connected to the air spring. There is a linear relationship between the pressure of the air spring and the applied normal force. Angular positions of the wheel and roller are measured by using two rotary encoders attached to the shafts of wheel and roller. Angular velocities are obtained by using a numerical derivation procedure for angular position measurements. In order to model coefficient of adhesion and measure tangential force between wheel and roller, a toque transducer is used and it is attached to the roller shaft. Finally, all sensory data is collected by a data acquisition device (i.e. DAQ) and processed by a computer.

Since the methodology proposed here is based on mathematical models, an accurate model of the considered system is essential. Therefore, models for subsystems and substructures are explained in the following subsections. The application of the general structure on the test stand is presented in Fig. 3.

\section{A. Electrical Motors}

Electrical layout of the test stand is reported in [12], [35]. A feedback flux weakening control method is used to drive PMSM connected to the tram wheel and details of the method are reported in [35]. During estimation process, torque profile is requested from this controller and the output of this control system is used. The asynchronous motor attached to the roller is used for maintaining a constant peripheral speed for the system and for braking. A volts per Hertz open loop control method is used for the asynchronous motor. In order to obtain mechanical torque exerted by this motor, firstly Thevenin equivalent circuit of the motor is obtained by no load test, blocked rotor test and measuring per phase stator resistances. Then, by using the following equation

$$
T_{\text {mech }}=\frac{3}{\omega_{\text {syn }}} \frac{V_{T h}^{2}}{\left(R_{T h}+\frac{R_{2}^{\prime}}{s}\right)^{2}+\left(X_{T h}+X_{2}^{\prime}\right)^{2}} \frac{R_{2}^{\prime}}{s_{m}},
$$

mechanical torque of the asynchronous motor can be calculated where $\omega_{\text {syn }}$ is the synchronous angular speed of the 


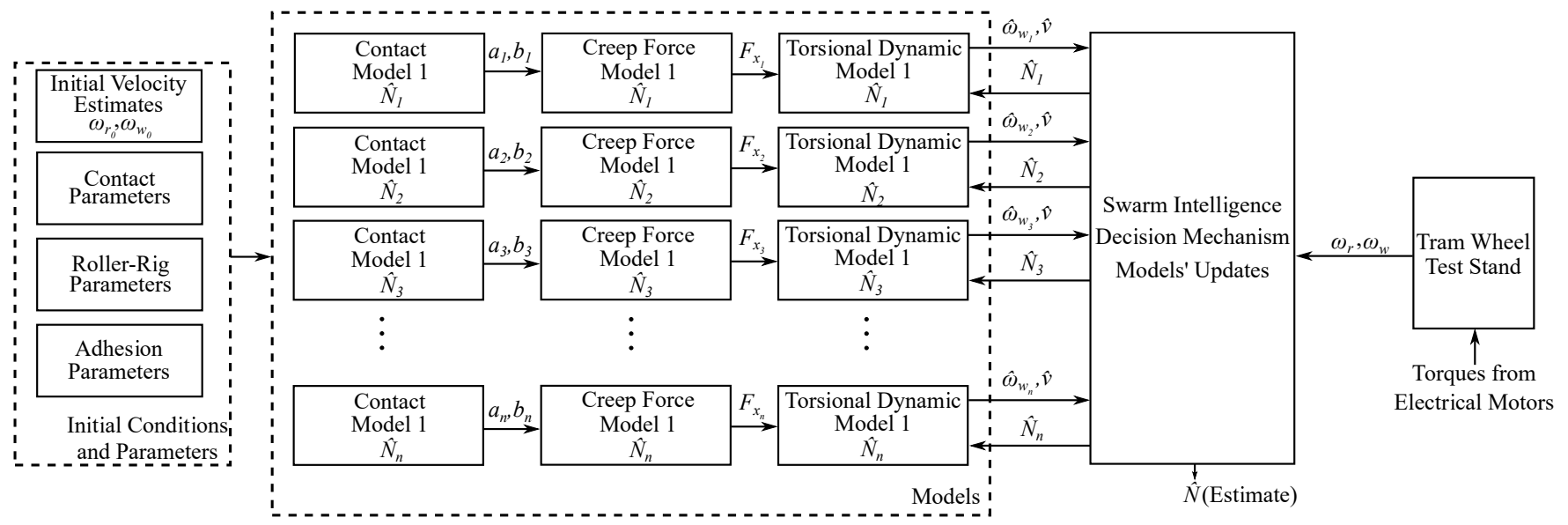

Fig. 3. Application of the methodology on a test stand

motor and $s_{m}$ is the slip which is simply the difference between rotor speed and synchronous speed, [36]. Parameters for the Thevenin equivalent circuit are provided in [12] for this test stand. Electrical motor parameters are same for all models, and they are illustrated in the roller-rig parameters section of Fig. 3.

\section{B. Contact Model}

1) Geometrical Investigation: One of the most critical models related with the methodology is the contact model. In order to build up the model, first step is to investigate the wheel-roller geometrical structure and interaction. Profiles of the wheel-roller are compatible with the wheel and rail profiles used in tram network of Prague, Czechia. Profile measurement is carried out by using a miniprof device. A diameter tape is considered to measure wheel-roller longitudinal rolling radii, and they are found as $0.6964 \mathrm{~m}$ and $0.9043 \mathrm{~m}$ for wheelroller, respectively. As well as longitudinal radii, lateral radii of the wheel-roller and conicity angle are also required to find a contact area. Therefore, a simple two point finite difference formula is considered to obtain longitudinal radii and conicity angle. Conicity angle of the wheel profile is expressed as

$$
\tan \delta_{w}=\frac{d z_{w}}{d y_{w}}
$$

where $\delta_{w}$ is the conicity angle, $z_{w}$ and $y_{w}$ are the vertical and lateral coordinates of the wheel profile. Lateral curvatures of the wheel-roller can be found as

$$
\kappa_{w, r}=\frac{\frac{d^{2} z_{w, r}}{d y_{w, r}^{2}}}{\left[1+\left(\frac{d z_{w, r}}{d y_{w, r}}\right)^{2}\right]^{\frac{3}{2}}},
$$

where indices $w$ and $r$ represents wheel-roller respectively. Results for the profile data, lateral curvatures and conicity angles are reported in [12].

Next step after obtaining profile data is to find a contact point. In order to find the contact point based on the profile data, quasi-elastic contact search method [37]-[39] is considered. Rigid contact search is the simplest method which is based on searching minimum vertical distance between profiles. Let $d\left(s, z_{w}, z_{r}\right)$ be the distance function between wheel-roller(rail) profiles where $s$ is the lateral distance of points with respect to the rigid contact point and $z_{w}$ and $z_{r}$ is the vertical coordinate of the wheel-roller profile, respectively. In quasi-elastic contact search, it is assumed that elastic deformations of both surfaces are related exponentially and the exponential weight function is given as

$$
w\left(s, z_{w}, z_{r}\right)=\exp \left(\frac{-d\left(s, z_{w}, z_{r}\right)}{\epsilon_{r e g}}\right),
$$

where $\epsilon_{r e g}$ is a regularization parameter, [38]. The elastic deformation of the wheel in pure elastic contact model is chosen as the indicator to determine regularization parameter and it is selected as $2 \times 10^{-5}$ which is the same value used in [37]. Thus, the location of new contact point based on the elasticity of the wheel and rail is found as

$$
\bar{s}=\frac{\int_{s_{\min }}^{s_{\max }} s \cdot w\left(s, z_{w}, z_{r}\right) d s}{\int_{s_{\min }}^{s_{\max }} w\left(s, z_{w}, z_{r}\right) d s} .
$$

Quasi-elastic contact search method determines new location of the contact point. Contact angle is obtained as 0.0503 rad by using (4) and the profile data obtained from miniprof device. As indicated previously, a simple two point finite difference formula for numerical differentiation is considered in (4). Likewise, lateral curvatures of the wheel and roller are obtained as 3.3406 and $0.5259 \mathrm{~m}^{-1}$, respectively by using (5). In other words, location of the contact point and profile data are considered to determine contact angle and lateral curvatures from (4) and (5).

2) Normal Problem Solution: Geometric investigation of profiles are required to obtain necessary parameters for the contact area. Theory of Hertz [40] is considered to find an elliptical contact area. In this theory, it is assumed that dimensions of each interacting body (e.g. wheel-rail) is much bigger than the dimensions of the contact area and the effect of tangential force due to the friction is neglected. The eccentricity of the elliptical contact area is defined as

$$
e=\sqrt{1-\frac{b^{2}}{a^{2}}}
$$


where $b<a$ are the semi-axes of the contact area. Pressure exerted on the contact is same for each body and equivalent elasticity modulus can be written as

$$
\frac{1}{E_{w r}}=\frac{1-\nu_{w}^{2}}{E_{w}}+\frac{1-\nu_{r}^{2}}{E_{r}}
$$

where $\nu_{w}$ and $\nu_{r}$ represents Poisson ratio of wheel-rail(roller), respectively.

In the method of Hertz, geometric constants based on principal curvatures of bodies are required. These constants are expressed as

$$
\begin{aligned}
& A=\frac{1}{4} {\left[\sum_{i=w, r}\left(\frac{1}{r_{i, x}}+\frac{1}{r_{i, y}}\right)-\left(\sum_{i=1}^{2}\left(\frac{1}{r_{i, x}}+\frac{1}{r_{i, y}}\right)^{2}+\right.\right.} \\
&\left.\left.2\left(\frac{1}{r_{w, x}}-\frac{1}{r_{w, y}}\right)\left(\frac{1}{r_{r, x}}-\frac{1}{r_{r, y}}\right) \cos 2 \psi_{h}\right)^{1 / 2}\right], \\
& B=\frac{1}{4} {\left[\sum_{i=w, r}\left(\frac{1}{r_{i, x}}+\frac{1}{r_{i, y}}\right)+\left(\sum_{i=1}^{2}\left(\frac{1}{r_{i, x}}+\frac{1}{r_{i, y}}\right)^{2}+\right.\right.} \\
&\left.\left.2\left(\frac{1}{r_{w, x}}-\frac{1}{r_{w, y}}\right)\left(\frac{1}{r_{r, x}}-\frac{1}{r_{r, y}}\right) \cos 2 \psi_{h}\right)^{1 / 2}\right] .
\end{aligned}
$$

where $r_{w, x}, r_{w, y}$ are the rolling radii of the wheel and $r_{r, x}, r_{r, y}$ are the rolling radii of the rail (roller) in the longitudinal and lateral directions, respectively, and $\psi_{h}$ is the angle between axes of wheel-rail (roller). In this case, it is assumed that $\psi_{h}$ equals to the contact angle. The ratio between these constants and the contact area is expressed as [41], [42]

$$
\frac{B}{A}=\frac{\left(\frac{a}{b}\right)^{2} \mathbf{E}(e)-\mathbf{K}(e)}{\mathbf{K}(e)-\mathbf{E}(e)}
$$

where $\mathbf{K}(e)$ and $\mathbf{E}(e)$ in these equations are the elliptical integrals of first and second kind of the eccentricity. Definitions of these integrals can be found in [43]. A semi-ellipsoidal pressure distribution in the contact area is assumed and the contact ellipse dimension [44] are found as

$$
\begin{aligned}
a & =\sqrt[3]{3 \frac{(\mathbf{K}(e)-\mathbf{E}(e)}{e^{2}} \frac{N}{2 \pi A E_{w r}},} \\
b & =a \sqrt{1-e^{2}}, \\
e & =\sqrt{1-\frac{b^{2}}{a^{2}}}=\sqrt{1-\frac{A}{B} \frac{\mathbf{E}(e)-\left(1-e^{2}\right) \mathbf{K}(e)}{\mathbf{K}(e)-\mathbf{E}(e)}},
\end{aligned}
$$

where $\mathrm{N}$ is the normal load. In order to compute the elliptical integrals of first and second kind, series expansion [45] around the point $e=0$ is taken into account and it can be given as

$$
\begin{array}{r}
\mathbf{K}(e)=\frac{\pi}{2}\left[1+\left(\frac{1}{2}\right)^{2} e^{2}+\left(\frac{1 \times 3}{2 \times 4}\right)^{2} e^{4}+\cdots+\right. \\
\left.\left(\frac{(2 n-1) ! !}{\left(2^{n} \times n !\right)}\right)^{2} e^{2 n}+\ldots\right], \\
\mathbf{E}(e)=\frac{\pi}{2}\left[1-\left(\frac{1}{2^{2}}\right) e^{2}-\left(\frac{1^{2} \times 3}{2^{2} \times 4^{2}}\right) e^{4}-\ldots\right. \\
\left.-\left(\frac{(2 n-1) ! !}{\left(2^{n} \times n !\right)}\right)^{2} \frac{e^{2 n}}{2 n-1}+\ldots\right],
\end{array}
$$

where $n$ represents the number of terms to approximate elliptical integrals. An iterative calculation is possible for these elliptical integrals [46] and it can be given as

$$
\begin{aligned}
& \mathbf{K}(e)=\sum_{n=1}^{\infty} P_{n}, \text { and }: P_{n+1}=P_{n}\left(\frac{2 n-1}{2 n}\right)^{2} e^{2}, \\
& \mathbf{E}(e)=\sum_{n=1}^{\infty} P_{n}, \text { and }: P_{n+1}=P_{n}\left(\frac{2 n-1}{2 n}\right)^{2} e^{2}\left(\frac{2 n-3}{2 n-1}\right) .
\end{aligned}
$$

Initial values for $P_{1}$ and $e$ is considered as $2 \pi$ and 0.5 , respectively. Maximum iteration is selected as $10^{3}$. It is stated in [45] that maximum error percentage for $\mathbf{K}_{e}$ and $\mathbf{E}_{e}$ are $30 \%$ and $6 \%$, respectively when only four terms (i.e. iterations) are used with an initial selection of $0 \leq e \leq 0.99$. Whereas, if initially $0 \leq e \leq 0.80$ is taken and four terms are selected, maximum error percentage for $\mathbf{K}_{e}$ and $\mathbf{E}_{e}$ are $2 \%$ and $0.4 \%$, respectively. In this study, if the highest term or the expansion is smaller than $10^{-6}$, iteration is terminated. Thus, eccentricity, dimensions of the contact area and elliptical integrals are calculated iteratively.

3) Shape Correction for the Contact Area: Investigations on the wheel-rail contact show that assumption of a smaller value of the penetration value than the Hertzian case provides closer results to the real contact shape. Thus, a virtual penetration value $\delta_{0}=0.55 \delta$ is selected in this study for shape correction [47], [48]. After shape correction, contact area dimensions can be calculated as

$$
\begin{aligned}
& a=\sqrt{\frac{0.55 \delta}{A}}, \\
& b=\sqrt{\frac{0.55 \delta}{B}} .
\end{aligned}
$$

It has been previously concluded that shape correction presented in [47] provides more promising results with respect to method of Hertz in comparison with the carbon paper test for the real contact patch [49] applied to the test stand considered in this study.

\section{Adhesion and Creep Force Model}

Experiments on the test stand are carried out for dry surface conditions. When slip increases, temperature at the contact increases and this cause a decrease in friction. A variable friction model proposed in [50], which considers the effect 
of the temperature, used here to model friction coefficient. Dimensionless creepage given for the wheel-rail case in (2) is considered for wheel-roller case, whereas spin creepage is not provided and for the wheel-roller it can be expressed as

$$
s_{\phi}=\frac{\sin \delta_{w}}{r_{e q_{x}}},
$$

where $\delta_{w}$ is the contact angle and $r_{e q_{x}}$ is the equivalent radius for wheel-roller and it is given as

$$
\frac{1}{r_{e q_{x}}}=\frac{1}{r_{w, x}}+\frac{1}{r_{r, x}}
$$

Friction coefficient between surfaces are defined as

$$
\mu=\mu_{0}\left[(1-A) e^{-B w}+A\right],
$$

where $\mu_{0}$ is the maximum friction coefficient, $w(\mathrm{~m} / \mathrm{s})$ is the magnitude of the slip velocity, $B(\mathrm{~s} / \mathrm{m})$ is the coefficient of exponential decrease and $A$ is the ratio of limit friction coefficient $\mu_{\infty}$ to $\mu_{0}$.

Creep force model reported in [50] is considered and it is expressed by

$$
F_{x}=-\frac{2 N \mu}{\pi}\left(\frac{k_{A} \epsilon}{1+\left(k_{A} \epsilon\right)^{2}}+\arctan k_{S} \epsilon\right), \quad k_{S} \leq k_{A} \leq 1,
$$

where $k_{A}$ and $k_{S}$ are reduction factors for adhesion and slip areas of contact area. $\epsilon$ is the initial gradient of the tangential stress and it is given as

$$
\epsilon=\frac{2}{3} \frac{C \pi a^{2} b}{N \mu} s
$$

where $C$ is the contact shear stiffness coefficient $\left(\mathrm{N} / \mathrm{m}^{3}\right)$. It is expressed as

$$
C=\frac{3}{8} \frac{G}{a} c_{j j},
$$

where $G$ is modulus of rigidity and it is assumed as $8 \times 10^{10} \mathrm{~Pa}$ and $c_{j j}$ where $j=1,2,3$ is the Kalker coefficients which are calculated and tabulated in [51]. A polynomial approximation for these coefficients are reported in Appendix A of [12]. $c_{j j}$ is expressed as

$$
c_{j j}=\sqrt{\left(c_{11} \frac{s_{x}}{s}\right)^{2}+\left(c_{22} \frac{s_{y}}{s}\right)^{2}}
$$

where $s=\sqrt{s_{x}^{2}+s_{y}^{2}}$ is the total creepage, $s_{x}$ and $s_{y}$ are the creepages and $c_{11}, c_{22}$ are Kalker coefficients in longitudinal and lateral directions, respectively. As stated previously, the effect of spin on the lateral creepage is taken into account here and the details of how spin creepage affects creep force is provided in [52].

Adhesion coefficient is defined as the ratio of tangential force to normal load and it is $f=\frac{F_{x}}{N}$. Adhesion is modeled by considering the measurements from the torque transducer and pressure transmitter, and for dry surface conditions maximum friction coefficient is determined as $\mu_{0}=0.4$, since only linear region of adhesion-creepage curve is measured. For other parameters standard particle swarm based optimization algorithm is considered and the parameters for this line is found as $A=0.6584, B=0.7087 \mathrm{~s} / \mathrm{m}, k_{A}=0.6258, k_{S}=0.5997$. Model and measurements of adhesion coefficient is presented in Fig. 4.

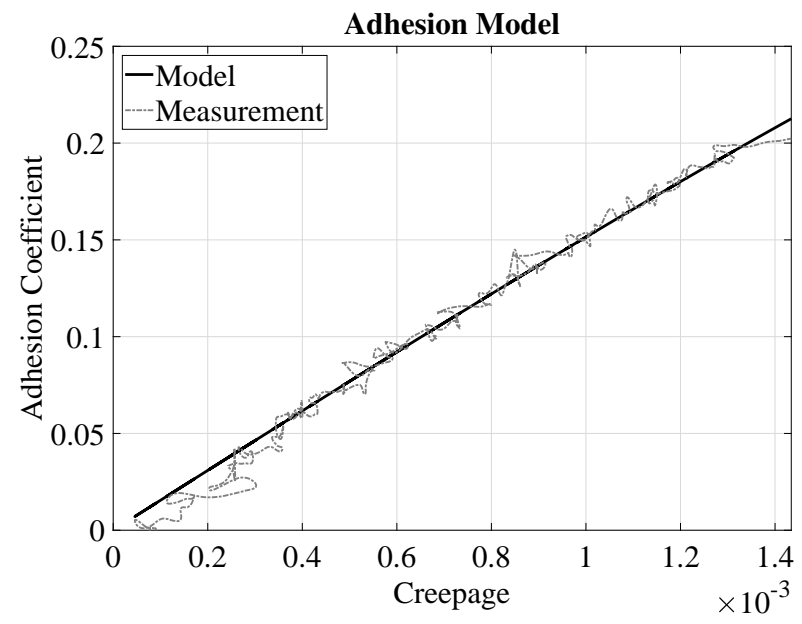

Fig. 4. Model and measurement for adhesion coefficient

\section{Torsional Dynamic Model of the Test Stand}

Forces and torques acting on the test stand are illustrated in Fig. 2a. Considering these forces and torques, dynamic model of the test stand is expressed as

$$
\begin{aligned}
\frac{d \dot{\omega}_{r}}{d t} & =\frac{T_{A}+\left(F_{x} \times r_{r, x}\right)}{J_{r_{\text {total }}}}, \\
\frac{d \dot{\omega}_{w}}{d t} & =\frac{-T_{P}-\left(F_{x} \times r_{w, x}\right)}{J_{w_{\text {total }}}},
\end{aligned}
$$

where $J_{w_{\text {total }}}$ and $J_{r_{\text {total }}}$ represents the total moment of inertias of the wheel-roller with connection elements, respectively. They are found as $17.86 \mathrm{kgm}^{2}$ and $47.2 \mathrm{kgm}^{2}$ by using a three dimensional modeling software. A fourth order RungeKutta numerical integration method is used to simulate the mathematical model given in (23). Time step is selected as $2.5 \times 10^{-4} \mathrm{~s}$.

\section{VAlidation of The Mathematical Model}

In order to validate the methodology, two peripheral velocities $5,16 \mathrm{~m} / \mathrm{s}$ and two loading cases $10,20 \mathrm{kN}$ are considered. In simulations, torque profile requested from the controller of PMSM is same and it is shown in Fig. 5.

In all simulations, maximum value of the torque request from the PMSM is same and it is approximately $785 \mathrm{~N} / \mathrm{m}$. It is apparent from the Fig. 6, 7, 8, 9 that mathematical model of the test stand is capable of tracking measurements. As well as wheel-roller angular velocities, creep force comparisons between model and measurements are also provided. It is seen from the Fig. 6, 8 and 7, 9 that creep force measurements are almost equal at same peripheral velocity for different normal loads. The main reason is that the torque requests from the 


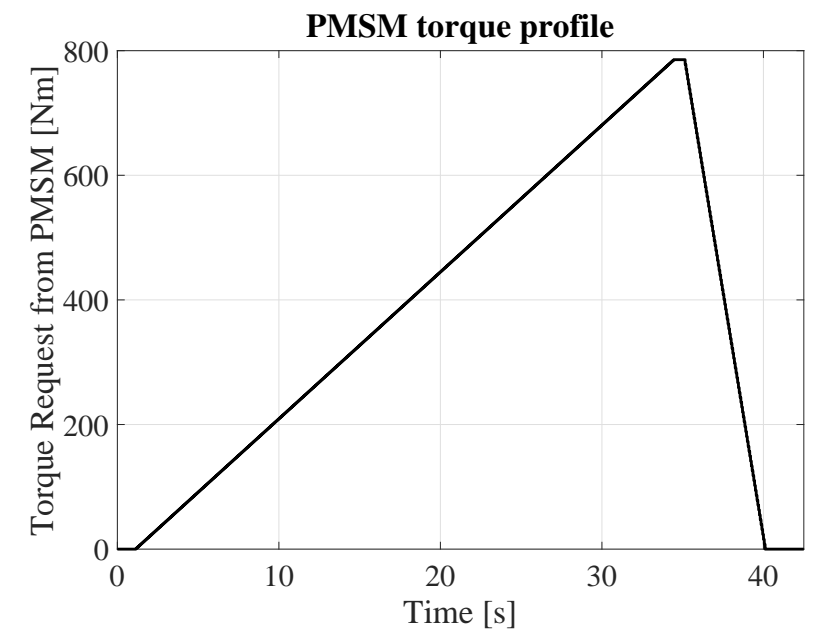

Fig. 5. Torque profile requested from the controller of PMSM

PMSM are almost equal and opposed torques from asynchronous motor are also equal for same peripheral velocities. However, creepage responses in both simulations for different normal loads are also different. Creepage measurement obtained from angular velocity measurements are shown in Fig. 10 , and as expected at $10 \mathrm{kN}$ creepage values are higher than the $20 \mathrm{kN}$ case for $5 \mathrm{~m} / \mathrm{s}$ peripheral velocity. The main idea behind the estimation methodology and the basis for the cost function in (1) is this fact that different creepage values occur for different normal loads at same velocities.

Moreover, noise in the measurements are seen in Figures. This noise is mainly due to the misalignment of connection elements and the main frequency component of the noise is directly proportional with the angular velocity of the roller. Therefore, effect of the noise can be significantly reduced by using a moving average filter based on the roller speed. Nevertheless, such filtering process is not considered for velocity measurements to show the effectiveness of the proposed methodology.

\section{Swarm Intelligence Based Multiple Models APPROACH}

During estimation process, multiple mathematical models of the test stand are created for different normal loads and all other mechanical, electrical parameters of the system are same for each model. Furthermore, a swarm intelligence based evolution of model estimates is proposed.

This methodology is tested firstly in [31], and it is inspired from the well-known particle swarm optimization. However, it is noticed in [31], [32] that the use of particle swarm optimization as a parameter estimator for this case is not suitable due to the noisy structure of the measurements. Therefore, unlike the noise free particle swarm optimization method, the global best model is omitted here due to the noisy structure of the measurements and a model reinitialization method proposed in [53] is considered. Other methods to consider particle swarm optimizer in noisy environments are summarized in [54], [55]. However, either noise statistics of the measurements must be known or complex PSO variants should be used in order to obtain promising results. In [55], two research strategies are proposed which are a weighted search center derived from the top-k best particles in the swarm and guiding the swarm by using the current fitness values rather than the historical ones. In this study, the methodology is based on the second strategy and the method is similar to the one proposed in [55], except they are proposing a dual approach which also includes the first strategy. It is already proven in [55] that historical information elimination (i.e. elimination of global best model), provides noise reduction in noisy environments.

The boundaries of the parameter space are selected as $\hat{N}_{\min }=4.2 \mathrm{kN}$ which is equal to bare weight of the wheel and $\hat{N}_{\max }=60 \mathrm{kN}$. Initial distribution of the normal loads for models are uniformly distributed between the limits. For example when five models are selected, the initial values for the normal load estimate vector $\hat{N}_{0}=$

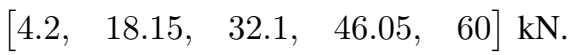

The sampling frequency of the measurements is $200 \mathrm{~Hz}$ and they are recorded. Thus, time step for the measurements is $5 \times 10^{-3} \mathrm{~s}$ and until a measurement is present, simulations are continued and when it is taken the velocity of the model estimates are updated based on

$$
V_{i}=\omega \times V_{i}+c \times r \times\left(\hat{N}_{\text {best }}-\hat{N}_{i}\right), \quad i=1, \ldots, N
$$

where $\omega$ is the inertia weight parameter and selected as 0.9 , $V_{i}$ is the velocity of the $i^{t h}$ model, $\hat{N}_{\text {best }}$ is the best estimate from previous time step which minimizes the cost function (1), $\hat{N}_{i}$ is the current parameter value for the $i^{t h}$ model, $c$ is the acceleration coefficient and it is selected as 2 and $r$ is a random number between $(0,1)$. Next step is to update normal load estimates based on the expression

$$
\hat{N}_{i}=\hat{N}_{i}+V_{i}
$$

In particle swarm optimization method, particles may diverge to large values. This can be prevented by using a velocity clamping method. In this study, clamping method proposed in [56] is used and it can be expressed as

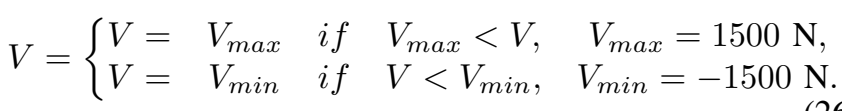

Furthermore, a model reinitialization method [53] is considered here in order to increase exploration capability of the estimation approach. When mean of the absolute value of the velocities are below a threshold value, models are reinitialized. $10 \mathrm{~N}$ is selected as the threshold for this application.

In order to reflect the behavior of the mathematical model with respect to different loading conditions, a test is carried out. For example, the cost function in (1) is illustrated in Fig. 11 when different normal loads are considered in the model. Three loads 8,10 and $12 \mathrm{kN}$ are selected, and (1) is realized. It is seen that the real parameter estimate is $10 \mathrm{kN}$ ( $5 \mathrm{~m} / \mathrm{s}$ peripheral velocity) and the cost function is minimized between 25-34 s in Fig. 11 for the real parameter value. This is due to the persistence of excitation [57] in parameter estimation of dynamic systems. Approximately $560 \mathrm{Nm}$ torque 


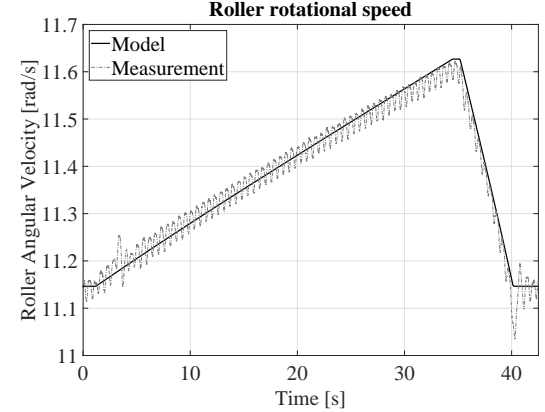

(a)

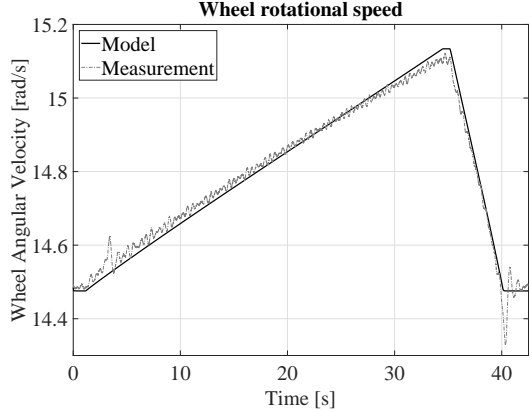

(b)

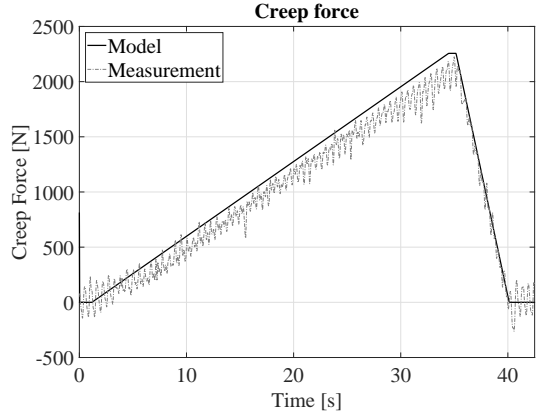

(c)

Fig. 6. Model validation for $5 \mathrm{~m} / \mathrm{s}$ and $10 \mathrm{kN}$ normal load

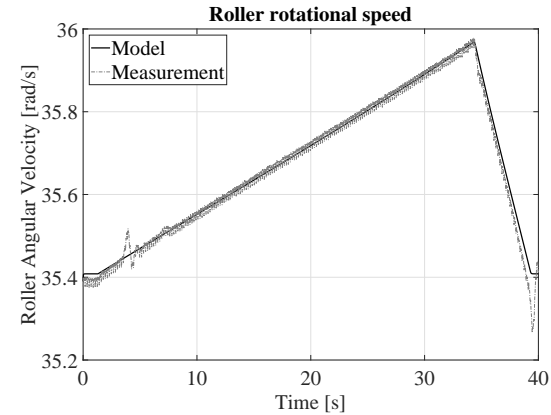

(a)

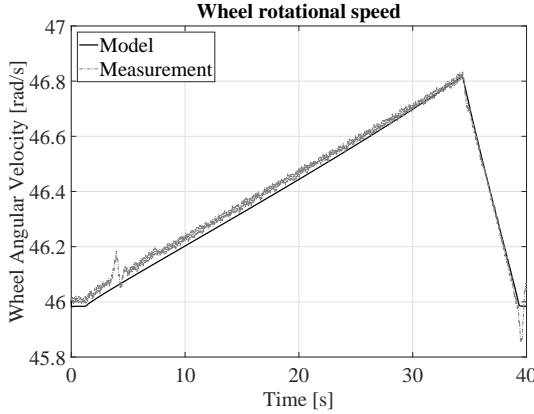

(b)

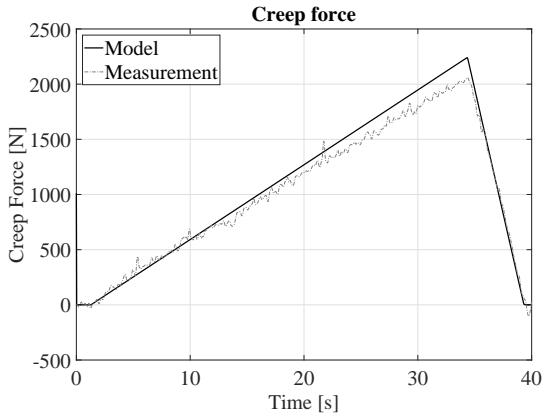

(c)

Fig. 7. Model validation for $16 \mathrm{~m} / \mathrm{s}$ and $10 \mathrm{kN}$ normal load

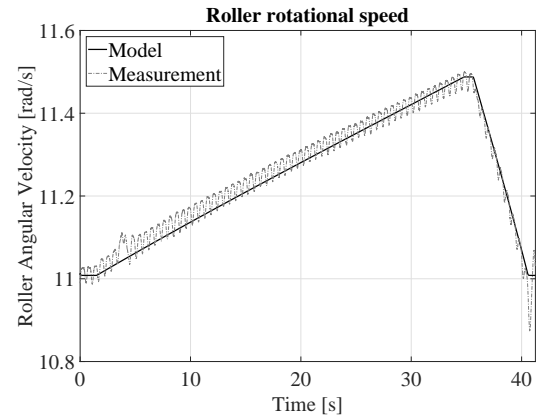

(a)

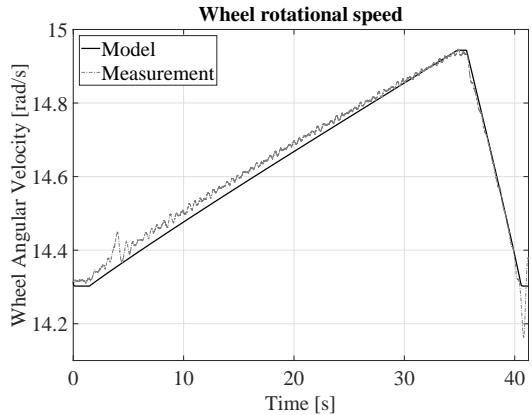

(b)

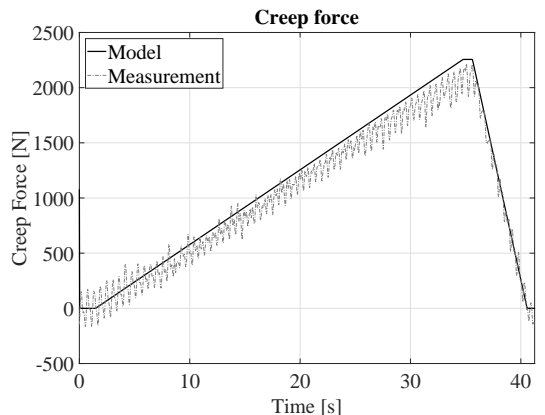

(c)

Fig. 8. Model validation for $5 \mathrm{~m} / \mathrm{s}$ and $20 \mathrm{kN}$ normal load

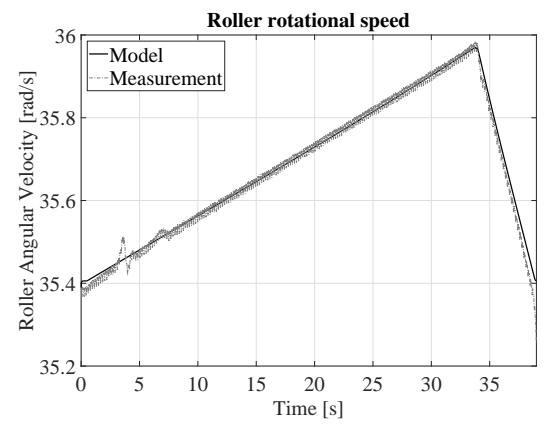

(a)

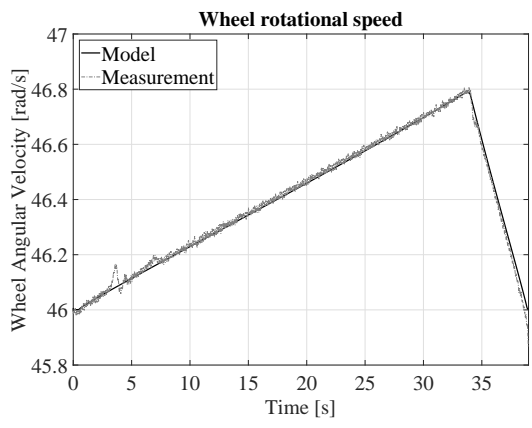

(b)

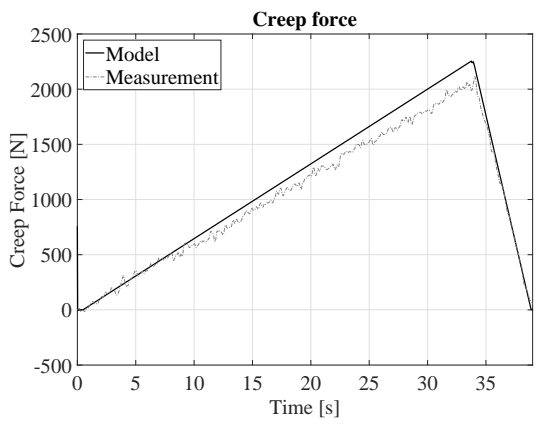

(c)

Fig. 9. Model validation for $16 \mathrm{~m} / \mathrm{s}$ and $20 \mathrm{kN}$ normal load 


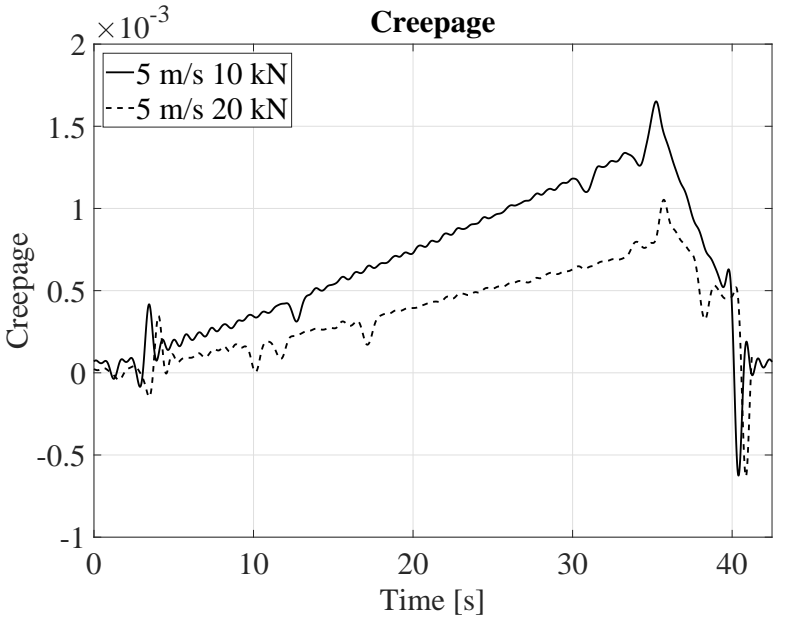

Fig. 10. Creepage comparison for 10 and $20 \mathrm{kN}$ at $5 \mathrm{~m} / \mathrm{s}$ peripheral velocity.

is selected for persistent excitation condition, and traction part of the torque profile in Fig. 5 ends at $34 \mathrm{~s}$. Therefore, this condition is taken into account during estimation process.

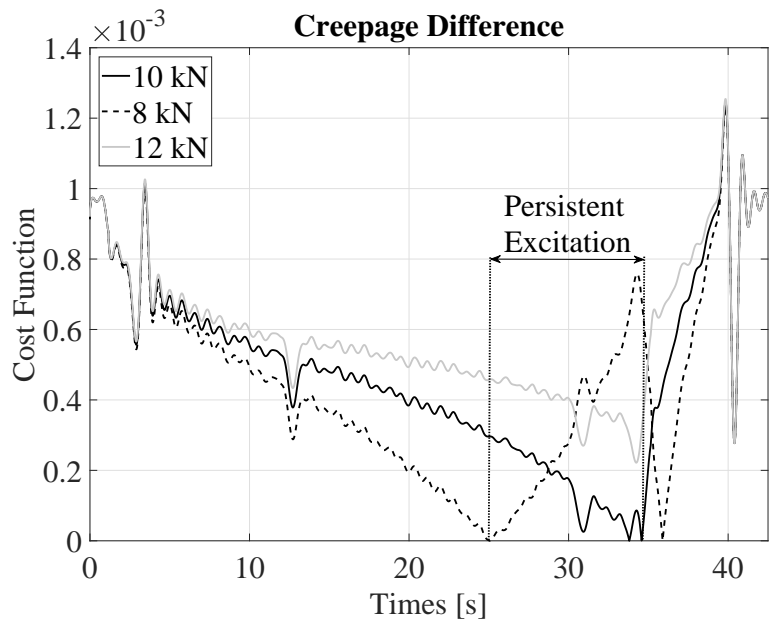

Fig. 11. Cost function (1) realization for different normal loads in model at $5 \mathrm{~m} / \mathrm{s}$ peripheral velocity and real normal load is $10 \mathrm{kN}$

\section{RESUlTS AND DISCUSSION}

Mathematical model is validated in a previous section. In addition to validation cases, one more peripheral velocity $10 \mathrm{~m} / \mathrm{s}$ is considered in this section. Firstly, the number of models is selected as five in order to show effectiveness of the methodology. However, the effect of number of models on results is discussed later in this section.

At $5 \mathrm{~m} / \mathrm{s}$ for $10 \mathrm{kN}$, estimation result can be seen in Fig. 12 . Nevertheless, this figure is provided to show the behavior of methodology for full time during estimation, and as indicated previously, the persistence of excitation condition is valid between 25-34 s and only this period is taken into account during estimation as presented in Fig. 13(a). Therefore, results for other cases are shown only for 25-34 s. Besides, it should be noted that effect of switching between models is apparent in estimation results. In order to decrease the effect of switching in the methodology, a moving average filter with an $1 \mathrm{~s}$ window length is considered. Estimation results for 10 and 20 $\mathrm{kN}$ are presented Fig. 13 and Fig. 14. In order to evaluate the estimator performance, root mean squared error (i.e. RMSE) is selected as the metric and it is expressed as

$$
e_{R M S}=\left[\frac{1}{M} \sum_{i=0}^{M}\left(N_{j}-\hat{N}_{j}\right)^{2}\right]^{\frac{1}{2}},
$$

where $j$ is the index for sample point and $M$ is the total number of samples. RMSE values are presented in Table I. It can be seen from the table that with increasing peripheral velocity estimation results degrade and with increasing normal load estimation results enhanced. The estimation methodology is promising that RMSE is below $7.24 \%$ in all cases.

Even though the estimation methodology is promising for the loading conditions 10 and $20 \mathrm{kN}$ where assumptions in Section III-B2 for Hertzian contact are valid, estimation methodology should also be tested for an excessive load for the tram wheel. Therefore, tests are carried out for $40 \mathrm{kN}$ normal load at same peripheral velocities, and results are provided in Fig. 16. It is previously proven in [58] that a double non-Hertzian contact areas occur on the same test stand for the excessive load $40 \mathrm{kN}$ and it can be seen in Fig. 15. Therefore, estimation results for $40 \mathrm{kN}$ are degraded in comparison with the 10 and $20 \mathrm{kN}$ loading conditions. RMSEs are found as $4319.9 \mathrm{~N}(\approx 10.80 \%), 6174.5 \mathrm{~N}(\approx 15.44 \%)$, $7260.7 \mathrm{~N}(\approx 18.15 \%)$ for $5,10,16 \mathrm{~m} / \mathrm{s}$ peripheral velocities, respectively. Even though the estimation results are not so good for the excessive load case, there is a promising aspect of the estimator which is overestimation. Estimator assumes an elliptical contact area, and it tries to simulate the real contact area so that it mostly overestimates the normal load since double contact occur in real case. Thus, excessive loading conditions, where contact area is no longer elliptical, can be detected easily. In order to enhance the estimator results for excessive loading case, non-Hertzian contact models [59], [60] must be considered, but such models are computationally expensive, and they increase the complexity of estimator.

It is assumed during validation process that the tram wheel is laterally fixed and this is a drawback for the approach. Therefore, this methodology can be applied for track sections with minimum lateral track irregularities. However, there are methodologies in the literature to estimate lateral track irregularities [61], [62] from acceleration measurements. Thus, this drawback of the methodology can be eliminated by combining this approach with these lateral position estimation methodologies.

Additionally, it is assumed in this study that angular velocity of the wheelset and translational velocity of the vehicle can be measured. This assumption is practical and there are studies which just focus on accurate speed estimation [63], [64]. Furthermore, there exists low cost and power solutions for accurate speed measurement [65]. Therefore, it is evident here that the speed measurement assumption is completely realistic and practical.

As previously emphasized, only five models are used for estimation. In Table II, the RMSE and computation time for 
5, 10 and 20 models are provided. $16 \mathrm{~m} / \mathrm{s}$ peripheral velocity and $10 \mathrm{kN}$ normal load case is considered for comparison. It is apparent from the results that even though the number of models increase, a significant decrease in RMSE is not obtained. However, when the number of models is doubled, computation time is doubled as well. Therefore, we concluded that 5 models is adequate for estimation. Simulations are carried out by using MATLAB [66] on a MacBook Pro Late 2011 laptop with a $2.8 \mathrm{GHz}$ dual-core Intel Core i7 processor and $8 \mathrm{~Gb}$ of RAM. Computation time is measured by using the stopwatch timer in MATLAB software. Another point about the complexity is that a $42.5 \mathrm{~s}$ simulation of physical system takes approximately $27 \mathrm{~s}$ computation time for one model. It can be objected that the real time application of the methodology is impractical, but it should be noted that simulations are carried out with a high level language such as MATLAB and computation times can be significantly improved by using low level languages such as $\mathrm{C}$ and $\mathrm{C}++$. Furthermore, there are multiprocessor system-on-chip methodologies [67] which use parallel processing to realize such mathematical models for railway vehicles. Therefore, the methodology proposed here can be applied in real time by considering the multiprocessor system-on-chip approaches and low level languages.

The use of test stands for validation and verification are quite common in the literature, [29], [32]. As indicated previously, the test stand used here for validation represents the traction system of the trams produced in Czechia and extension of this methodology on these vehicles in operation is straightforward and it can also be applied directly for locomotives and hauled stock with traction. Dynamic models similar to for vehicles in operation. Nevertheless, in order to apply this methodology for hauled stock without traction, different mathematical models should be considered since a persistent excitation is needed to estimate normal load as a parameter. Fortunately, there is a source of such excitation in wheel-rail case, and it is track irregularity. Especially, vertical dynamic model of the hauled stock can be used along with the methodology proposed here for the track sections with known or estimated vertical track irregularities [68] so that normal load estimation is made possible for hauled stock. Such normal load estimation is proposed in [28] with an inverse dynamic model but the maximum correlation coefficient is about $0.73 \%$ and it is not suitable for practical purposes.

It is convenient to compare the accuracy of this methodology with previous approaches [28]-[30] which are referred as indirect in [25]. In [28], it is stated that maximum correlation coefficient between the measurements from field tests and estimated value for vertical force is 0.73 and this is not a promising result in comparison with the results provided here. An indicator of the accuracy is not provided in [29], whereas it is reported graphically in comparison with the conventional method (i.e. instrumented wheelset). Therefore, a direct comparison cannot be carried out with [29]. Likewise, the results of the methodology proposed in [30] are compared with the results of the conventional method and it is stated that the maximum error for estimated vertical force is about $10 \%$ which is also higher than the worst results reported here. Accuracy is not explicitly provided in studies based
TABLE I

RMSE VALUES FOR TEST CASES

\begin{tabular}{cccc}
\hline & $5 \mathrm{~m} / \mathrm{s}$ & $10 \mathrm{~m} / \mathrm{s}$ & $16 \mathrm{~m} / \mathrm{s}$ \\
\hline $10 \mathrm{kN}$ & $702.5306 \mathrm{~N}$ & $707.7997 \mathrm{~N}$ & $729.8672 \mathrm{~N}$ \\
& $(\approx 6.96 \%)$ & $(\approx 7.02 \%)$ & $(\approx 7.24 \%)$ \\
\hline $20 \mathrm{kN}$ & $751.8557 \mathrm{~N}$ & $884.5426 \mathrm{~N}$ & $1389.500 \mathrm{~N}$ \\
& $(\approx 3.76 \%)$ & $(\approx 4.42 \%)$ & $(\approx 6.95 \%)$ \\
\hline
\end{tabular}

on instrumented wheelsets or special sensors [25], [26], and experimental validation is not provided and mentioned as a further work for track based WIM systems [20], [22]. Therefore, it is inconvenient to compare the accuracy of this methodology with these previous studies. Furthermore, completely different and indirect approach is proposed here with sensors which are used for velocity measurements and traction control, unlike the use of force sensitive elements for direct estimation. In [23], it is reported that the accuracy of the WIM system used in North American railroads is $98 \%$ after static calibration, but it is also indicated that in a relative small speed range, the measured weight is similar to the actual weight by an offset. Elimination of this offset is left as further work in [23]. In [20], [22], the accuracy is also reported as 98\%, but this approach is validated based on multibody system simulations and experimental validation is not provided and left as further work.

The approach presented here brings several advantages in comparison with the previous studies. First of all, as stated by [21], track based solutions are sensitive to the environmental conditions and the dynamic motion of the vehicle. Therefore, the calibration of these systems must be carried out periodically, [23]. However, the sensors considered in this methodology do not require additional calibration for load estimation since they are already used for different purposes (e.g. speed calculation, traction control). Secondly, previous WIM systems require special and specific instrumentation for application, this is expensive and require extra labor for implementation, maintenance and calibration, [23].

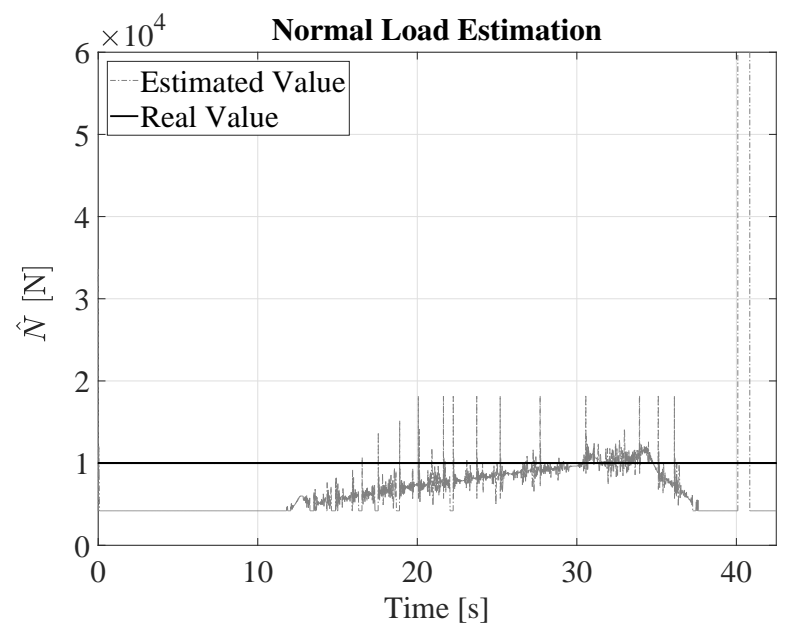

Fig. 12. Estimation result for whole simulation at $5 \mathrm{~m} / \mathrm{s}$ peripheral velocity and normal load is $10 \mathrm{kN}$ 


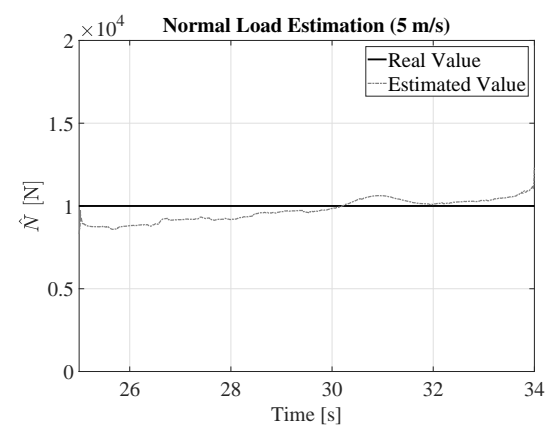

(a) $5 \mathrm{~m} / \mathrm{s}$

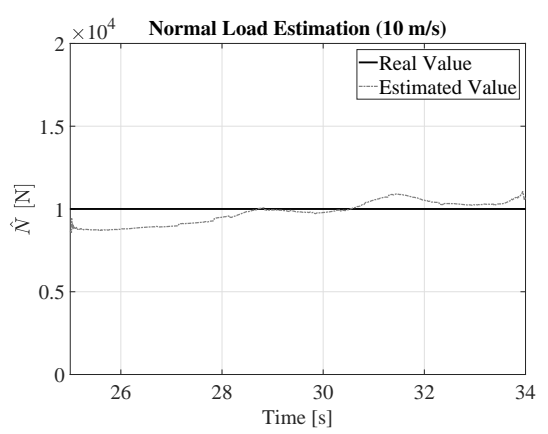

(b) $10 \mathrm{~m} / \mathrm{s}$

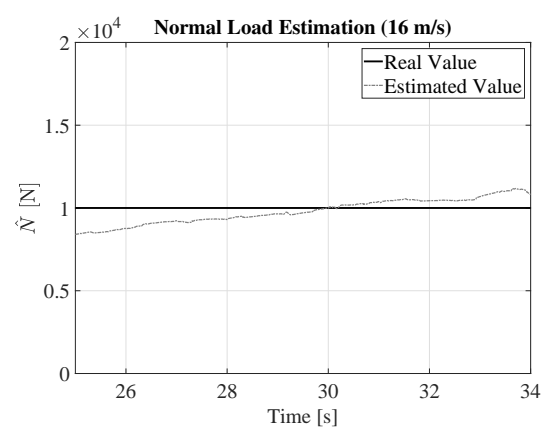

(c) $16 \mathrm{~m} / \mathrm{s}$

Fig. 13. Filtered estimation results between $25-34$ s, normal load is $10 \mathrm{kN}$

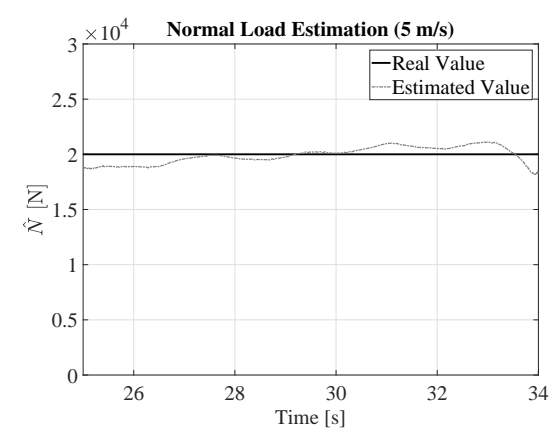

(a) $5 \mathrm{~m} / \mathrm{s}$

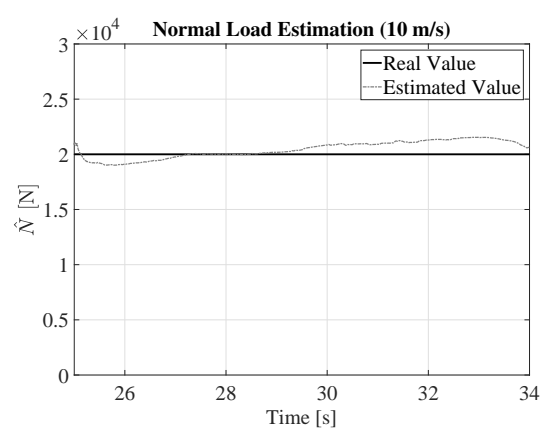

(b) $10 \mathrm{~m} / \mathrm{s}$

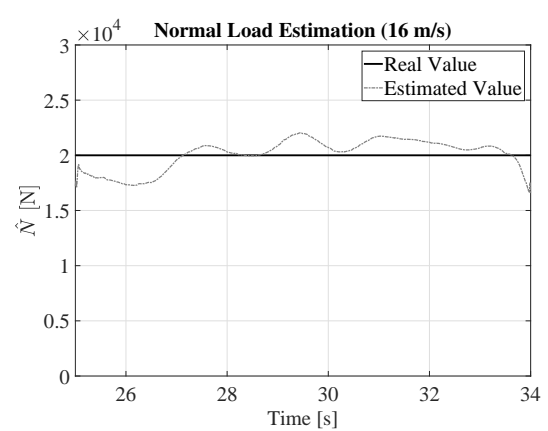

(c) $16 \mathrm{~m} / \mathrm{s}$

Fig. 14. Filtered estimation results between $25-34 \mathrm{~s}$, normal load is $20 \mathrm{kN}$

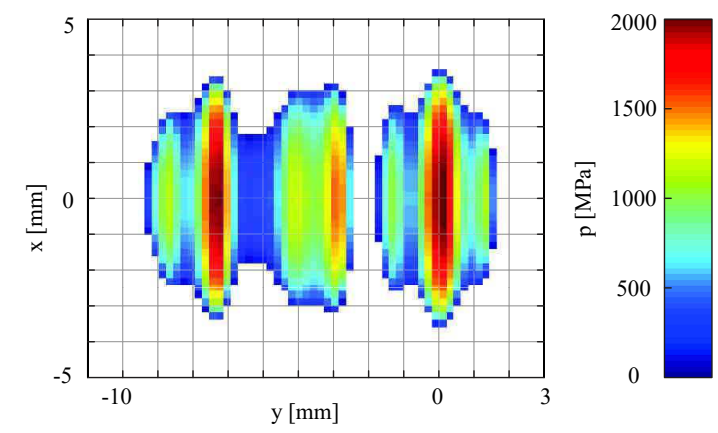

Fig. 15. Contact area for a $40 \mathrm{kN}$ normal load on the tram wheel, figure from [58] and contact area is obtained by CONTACT software [69].

TABLE II

RMSE VALUES AND COMPUTATION TIMES FOR 5, 10, 20 MODELS

\begin{tabular}{cccc}
\hline & 5 Models & 10 Models & 20 Models \\
\hline RMSE & $729.8672 \mathrm{~N}$ & $722.5025 \mathrm{~N}$ & $717.8344 \mathrm{~N}$ \\
& $(\approx 7.24 \%)$ & $(\approx 7.16 \%)$ & $(\approx 7.12 \%)$ \\
\hline Computation Time & $135.438 \mathrm{~s}$ & $273.8605 \mathrm{~s}$ & $532.7294 \mathrm{~s}$ \\
\hline
\end{tabular}

\section{CONCLUSION}

In this study, a mathematical model based normal load estimation is proposed. A particle swarm optimization based model evolution for models is presented. Firstly, mathematical model is validated by considering measurements taken from the roller-rig. Then, the methodology is proven on a tram wheel test stand which simulates traction system of some trams produced in Czechia. Estimation methodology is promising to be used as a standalone monitoring tool for railway vehicles with traction. Moreover, this methodology can be used along with the track sensor-based WIM systems so that the number of sensors, which should be placed to track sections, can be significantly reduced.

As presented previously, WIM systems can be categorized based on the replacement of sensors either to the track side or vehicle. Furthermore, estimation of normal load by using vehicle based sensors can be categorized as direct and indirect. Direct estimation is based on the design of specific sensors for this purpose, whereas indirect estimation strategies are based on using sensors which are already used for other purposes in vehicle. Comparison of the results of this study with previous works in previous section demonstrates that the methodology proposed here provides the most promising results among the indirect estimation schemes presented previously in the literature to the authors' knowledge. However, a clear comparison of the methodology with respect to track based estimation methodologies cannot be given, since either some of them [20], [22] are simulation based or the accuracy of the results are corrected by considering an offset [23]. A standard metric for accuracy after static calibration is presented in [23] as 98\% for North American railroads. However, in the dynamic case, it is obvious that such accuracy cannot be reached.

Such methodology can also be considered to inspect safety against derailment [70]. For example, Nadal's flange climb criterion is expressed as [70] 


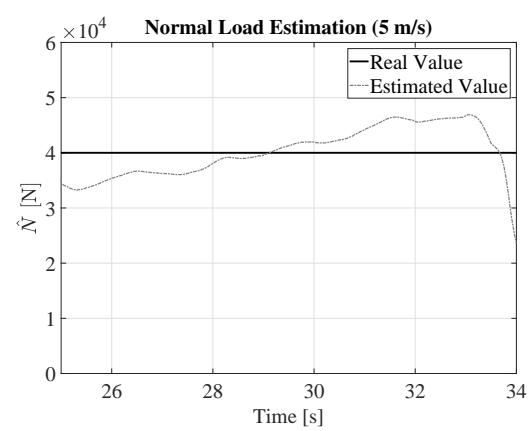

(a) $5 \mathrm{~m} / \mathrm{s}$

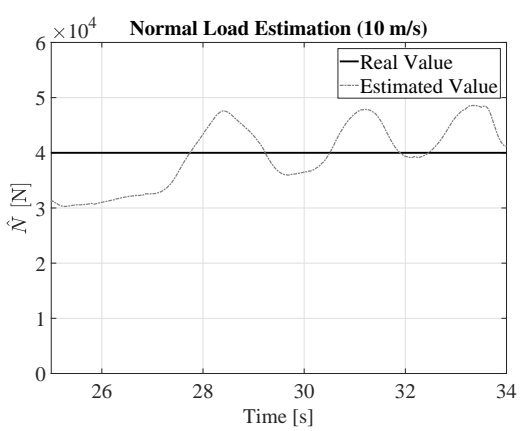

(b) $10 \mathrm{~m} / \mathrm{s}$

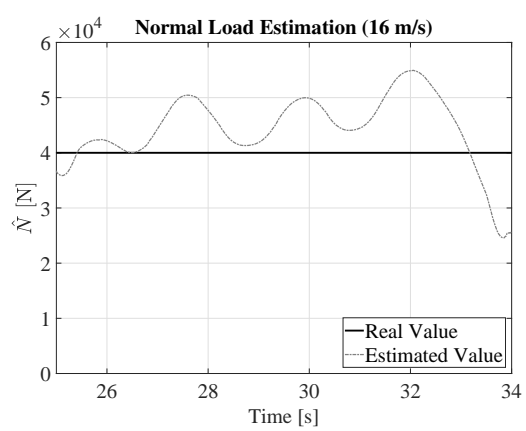

(c) $16 \mathrm{~m} / \mathrm{s}$

Fig. 16. Filtered estimation results between $25-34$ s, normal load is $40 \mathrm{kN}$

$$
\left(\frac{Y}{Q}\right)_{l i m}=\frac{\tan \gamma-0.36}{1+0.36 \tan \gamma}
$$

where $Y$ is the lateral force, $Q$ is the normal load, 0.36 is the considered friction coefficient and $\gamma$ is the flange angle. Especially, measurements to determine the limit for such criterion are carried out either by using instrumented tracks or wheelsets. In case of flange contact, Hertzian contact conditions are not valid and for such case previously stated non-Hertzian contact models can be considered or since the methodology with Hertzian contact assumption cause an overestimation, maximum result of the estimator can be considered with a safety margin of $\approx 20 \%$ depending on the translational velocity. It should be noted that maximum speed considered here $16 \mathrm{~m} / \mathrm{s}(\approx 60 \mathrm{~km} / \mathrm{h})$ is an excessive speed for a tram wheel. Therefore, when a locomotive wheelset is considered methodology proposed here can be tested for higher translational velocities.

One of the further works is to use a state filter to enhance estimation results. Instead of directly using the results of models, state estimators such as family of Kalman filters can be used. If such a state estimator is considered along with a non-Hertzian contact model, which better describes the contact area for flange contact, estimator result can be enhanced beyond the results of this study. Nevertheless, such state estimators and non-Hertzian contact models come with computational complexity drawback. Recently, the first author proposed a computationally efficient joint unscented Kalman filter for parameter estimation in [71], and currently, authors are working on combining the swarm intelligence based parameter estimation methodology proposed here with the joint unscented Kalman filter by using the same methodology in [71] to enhance the normal load estimation. Therefore, in further work, even $98 \%$ accuracy, which is the value for North American railroads after static calibration of track based WIM systems, can be achieved.

Another further work is to test this methodology for hauled stock by considering a vertical dynamic model of a vehicle. Persistent excitation can be obtained by considering the track irregularities so that the model based methodology can be promising to estimate vertical wheel loads in case of hauled stock.

\section{ACKNOWLEDGMENT}

The authors are grateful to doc. Ing. Petr Voltr, Ph.D. from University of Pardubice, Czechia for his comments and support for this work.

The authors also would like to thank doc. Ing. Michael Lata, Ph.D. from university of Pardubice, Czechia.

First author would like to thank prof. Ing. Jaroslav Novák, CSc. from university of Pardubice, Czechia for his help and patience during the measurements from asynchronous motor.

\section{FUNDING}

This work is supported by University of Pardubice, Czechia and Eskisehir Technical University, Turkey.

\section{REFERENCES}

[1] C. Li, S. Luo, C. Cole, and M. Spiryagin, "An overview: modern techniques for railway vehicle on-board health monitoring systems," Vehicle system dynamics, vol. 55, no. 7, pp. 1045-1070, 2017.

[2] I. Hussain, T. Mei, and R. Ritchings, "Estimation of wheel-rail contact conditions and adhesion using the multiple model approach," Vehicle System Dynamics, vol. 51, no. 1, pp. 32-53, 2013.

[3] P. Hubbard, C. Ward, R. Dixon, and R. Goodall, "Real time detection of low adhesion in the wheel/rail contact," Proceedings of the Institution of Mechanical Engineers, Part F: Journal of Rail and Rapid Transit, vol. 227, no. 6, pp. 623-634, 2013.

[4] A. Onat, P. Voltr, and M. Lata, "A new friction condition identification approach for wheel-rail interface," International Journal of Rail Transportation, vol. 5, no. 3, pp. 127-144, 2017.

[5] P. D. Hubbard, N. Farhat, C. P. Ward, and G. Amarantidis, "Contact force estimation in the wheel/rail interface for curving scenarios through regions of reduced adhesion," Mechatronics, 2017.

[6] C. Delprete and C. Rosso, "An easy instrument and a methodology for the monitoring and the diagnosis of a rail," Mechanical Systems and Signal Processing, vol. 23, no. 3, pp. 940-956, 2009.

[7] M. Molodova, Z. Li, and R. Dollevoet, "Axle box acceleration: Measurement and simulation for detection of short track defects," Wear, vol. 271, no. 1-2, pp. 349-356, 2011.

[8] H. Tsunashima, Y. Naganuma, A. Matsumoto, T. Mizuma, and H. Mori, "Condition monitoring of railway track using in-service vehicle," in Reliability and safety in railway. InTech, 2012.

[9] M. Molodova, Z. Li, A. Núñez, and R. Dollevoet, "Automatic detection of squats in railway infrastructure," IEEE Transactions on Intelligent Transportation Systems, vol. 15, no. 5, pp. 1980-1990, 2014.

[10] B. Liang, S. Iwnicki, Y. Zhao, and D. Crosbee, "Railway wheelflat and rail surface defect modelling and analysis by time-frequency techniques," Vehicle System Dynamics, vol. 51, no. 9, pp. 1403-1421, 2013.

[11] A. Alemi, F. Corman, and G. Lodewijks, "Condition monitoring approaches for the detection of railway wheel defects," Proceedings of the Institution of Mechanical Engineers, Part F: Journal of Rail and Rapid Transit, vol. 231, no. 8, pp. 961-981, 2017. 
[12] A. Onat, P. Voltr, and M. Lata, "An unscented kalman filter-based rolling radius estimation methodology for railway vehicles with traction," Proceedings of the Institution of Mechanical Engineers, Part F: Journal of Rail and Rapid Transit, 2017.

[13] N. Bosso, A. Gugliotta, and N. Zampieri, "Wheel flat detection algorithm for onboard diagnostic," Measurement, 2018.

[14] P. Li, R. Goodall, P. Weston, C. S. Ling, C. Goodman, and C. Roberts, "Estimation of railway vehicle suspension parameters for condition monitoring," Control engineering practice, vol. 15 , no. 1, pp. 43-55, 2007.

[15] M. Jesussek and K. Ellermann, "Fault detection and isolation for a nonlinear railway vehicle suspension with a hybrid extended kalman filter," Vehicle System Dynamics, vol. 51, no. 10, pp. 1489-1501, 2013.

[16] X. Wei, L. Jia, and H. Liu, "A comparative study on fault detection methods of rail vehicle suspension systems based on acceleration measurements," Vehicle System Dynamics, vol. 51, no. 5, pp. 700-720, 2013.

[17] X. Wei, L. Jia, K. Guo, and S. Wu, "On fault isolation for rail vehicle suspension systems," Vehicle System Dynamics, vol. 52, no. 6, pp. 847$873,2014$.

[18] M. Jesussek and K. Ellermann, "Fault detection and isolation for a fullscale railway vehicle suspension with multiple kalman filters," Vehicle System Dynamics, vol. 52, no. 12, pp. 1695-1715, 2014.

[19] A. Onat, O. Kılınç, and M. Lata, "A linear kalman filtering scheme for estimation of secondary vertical suspension of railway vehicles," in The 21st VIBROENGINEERING Conference, vol. 7, 2016, pp. 124-128.

[20] P. D'Adamio, L. Marini, E. Meli, L. Pugi, and A. Rindi, "Development of a dynamical weigh in motion system for railway applications," Meccanica, vol. 51, no. 10, pp. 2509-2533, 2016.

[21] K. Sekuła and P. Kołakowski, "Piezo-based weigh-in-motion system for the railway transport," Structural Control and Health Monitoring, vol. 19, no. 2, pp. 199-215, 2012.

[22] B. Allotta, P. D'Adamio, L. Marini, E. Meli, L. Pugi, and A. Rindi, "A new strategy for dynamic weighing in motion of railway vehicles," IEEE Transactions on Intelligent Transportation Systems, vol. 16, no. 6, pp. 3520-3533, 2015.

[23] Y. Ding and L. R. Cheng, "Dynamic calibration of a weigh in motion system," p. V001T03A007, 2018. [Online]. Available: http://dx.doi.org/10.1115/JRC2018-6222

[24] V. R. Bagheri, D. Younesian, and P. H. Tehrani, "A new methodology for the estimation of wheel-rail contact forces at a high-frequency range," Proceedings of the Institution of Mechanical Engineers, Part F: Journal of Rail and Rapid Transit, vol. 232, no. 10, pp. 2353-2370, 2018. [Online]. Available: https://doi.org/10.1177/0954409718771746

[25] Y. Ren and J. Chen, "A new method for wheel-rail contact force continuous measurement using instrumented wheelset," Vehicle System Dynamics, vol. 57, no. 2, pp. 269-285, 2019. [Online]. Available: https://doi.org/10.1080/00423114.2018.1460853

[26] A. Matsumoto, Y. Sato, H. Ohno, M. Shimizu, J. Kurihara, T. Saitou, Y. Michitsuji, R. Matsui, M. Tanimoto, and M. aki Mizuno, "Actual states of wheel/rail contact forces and friction on sharp curves - continuous monitoring from in-service trains and numerical simulations," Wear, vol. 314, no. 1, pp. 189 - 197, 2014, proceedings of the 9th International Conference on Contact Mechanics and Wear of Rail / Wheel Systems, Chengdu, 2012. [Online]. Available: http://www.sciencedirect.com/science/article/pii/S0043164813005905

[27] A. Matsumoto, Y. Sato, H. Ohno, M. Shimizu, J. Kurihara, M. Tomeoka, T. Saitou, Y. Michitsuji, M. Tanimoto, Y. Sato, and M. Mizuno, "Continuous observation of wheel/rail contact forces in curved track and theoretical considerations," Vehicle System Dynamics, vol. 50, no. sup1, pp. 349-364, 2012. [Online]. Available: https://doi.org/10.1080/00423114.2012.669130

[28] T. Uhl, "The inverse identification problem and its technical application," Archive of Applied Mechanics, vol. 77, no. 5, pp. 325-337, May 2007. [Online]. Available: https://doi.org/10.1007/s00419-006-0086-9

[29] A. Matsumoto, Y. Sato, H. Ohno, M. Tomeoka, K. Matsumoto, J. Kurihara, T. Ogino, M. Tanimoto, Y. Kishimoto, Y. Sato et al., "A new measuring method of wheel-rail contact forces and related considerations," Wear, vol. 265, no. 9-10, pp. 1518-1525, 2008.

[30] L. Wei, J. Zeng, P. Wu, and H. Gao, "Indirect method for wheel-rail force measurement and derailment evaluation," Vehicle System Dynamics, vol. 52, no. 12, pp. 1622-1641, 2014. [Online]. Available: https://doi.org/10.1080/00423114.2014.953180

[31] A. Onat and P. Voltr, "Swarm intelligence based multiple model approach for friction estimation at wheel-rail interface," in 5th International Symposium on Engineering, Artificial Intelligence and Applications, ISEAIA 2017, 2017, pp. 187-194.
[32] — "Velocity measurement based friction estimation for railway vehicles running on adhesion limit: Swarm intelligence based multiple models approach," Journal of Intelligent Transportation Systems, 2018.

[33] P. Voltr and M. Lata, "Transient wheel-rail adhesion characteristics under the cleaning effect of sliding," Vehicle System Dynamics, vol. 53 no. 5 , pp. 605-618, 2015 .

[34] G. Trummer, L. Buckley-Johnstone, P. Voltr, A. Meierhofer, R. Lewis, and K. Six, "Wheel-rail creep force model for predicting water induced low adhesion phenomena," Tribology International, vol. 109, pp. 409415, 2017.

[35] R. Doleček, J. Novák, and O. Černỳ, "Traction permanent magnet synchronous motor torque control with flux weakening," Radioengineering, vol. 18 , no. 4 , pp. 601-605, 2009.

[36] P. C. Sen, Principles of electric machines and power electronics. John Wiley \& Sons, 2007.

[37] M. Arnold and H. Netter, "Wear profiles and the dynamical simulation of wheel-rail systems," in Progress in Industrial Mathematics at ECMI 96. Springer, 1997, pp. 77-84.

[38] H. Netter, G. Schupp, W. Rulka, and K. Schroeder, "New aspects of contact modelling and validation within multibody system simulation of railway vehicles," Vehicle System Dynamics, vol. 29, no. S1, pp. 246269, 1998.

[39] G. Schupp, C. Weidemann, and L. Mauer, "Modelling the contact between wheel and rail within multibody system simulation," Vehicle System Dynamics, vol. 41, no. 5, pp. 349-364, 2004.

[40] H. Hertz, "Über die berührung fester elastischer körper." Journal für die reine und angewandte Mathematik, vol. 92, pp. 156-171, 1881.

[41] A. Onat, P. Voltr, and M. Lata, "Nonlinear wheel/rail contact geometry characteristics \& determination of hertzian contact," Scientific papers of the University of Pardubice (Series B), vol. 19, pp. 145-152, 2014.

[42] K. L. Johnson, Contact mechanics. Cambridge university press, 1985.

[43] A. A. Shabana, K. E. Zaazaa, and H. Sugiyama, Railroad vehicle dynamics: a computational approach. CRC press, 2007.

[44] A. Onat, "Estimation of states and parameters from dynamic response of wheelset," Ph.D. dissertation, University of Pardubice, 32017.

[45] A. R. Vatankhah, "Approximate solutions to complete elliptic integrals for practical use in water engineering," Journal of Hydrologic Engineering, vol. 16, no. 11, pp. 942-945, 2011.

[46] T. Michálek, "Namáhání v kontaktní ploše mezi kolem a kolejnicí [loading in the contact area of wheel and rail]," Student Work, 2008, in Czech.

[47] J. Piotrowski and W. Kik, "A simplified model of wheel/rail contact mechanics for non-hertzian problems and its application in rail vehicle dynamic simulations," Vehicle System Dynamics, vol. 46, no. 1-2, pp. 27-48, 2008.

[48] M. S. Sichani, R. Enblom, and M. Berg, "Comparison of non-elliptic contact models: Towards fast and accurate modelling of wheel-rail contact," Wear, vol. 314, no. 1-2, pp. 111-117, 2014.

[49] Y. Ozdemir and P. Voltr, "Contact between wheel and "rotating rail" on a roller rig," in 33th International Colloquium-Advanced Manufacturing and Repair Technologies in Vehicle Industry, 2016.

[50] O. Polach, "Creep forces in simulations of traction vehicles running on adhesion limit," Wear, vol. 258, no. 7-8, pp. 992-1000, 2005.

[51] J. J. Kalker, "On the rolling contact of two elastic bodies in the presence of dry friction," Ph.D. dissertation, TU Delft, Delft University of Technology, 1967.

[52] O. Polach, "A fast wheel-rail forces calculation computer code," Vehicle System Dynamics, vol. 33, pp. 728-739, 2000.

[53] K. J. Binkley and M. Hagiwara, "Balancing exploitation and exploration in particle swarm optimization: velocity-based reinitialization," Information and Media Technologies, vol. 3, no. 1, pp. 103-111, 2008.

[54] M. Zhou, Z. Zhao, C. Xiong, and Q. Kang, "An opposition-based particle swarm optimization algorithm for noisy environments," in 2018 IEEE 15th International Conference on Networking, Sensing and Control (ICNSC), March 2018, pp. 1-6.

[55] J. Zhang, X. Zhu, Y. Wang, and M. Zhou, "Dual-environmental particle swarm optimizer in noisy and noise-free environments," IEEE Transactions on Cybernetics, pp. 1-11, 2018.

[56] F. Shahzad, S. Masood, and N. K. Khan, "Probabilistic opposition-based particle swarm optimization with velocity clamping," Knowledge and information systems, vol. 39, no. 3, pp. 703-737, 2014.

[57] M. Demetriou and I. Rosen, "On the persistence of excitation in the adaptive estimation of distributed parameter systems," IEEE transactions on automatic control, vol. 39, no. 5, pp. 1117-1123, 1994.

[58] P. Voltr, "Měřní a modelování adheze kola a kolejnice (Measurement and modelling of wheel-rail adhesion)," 2017, Habilitation thesis, Univerzita Pardubice (University of Pardubice), In Czech. 
[59] J. Kalker, "Survey of wheel—rail rolling contact theory," Vehicle system dynamics, vol. 8, no. 4, pp. 317-358, 1979.

[60] M. Sh. Sichani, R. Enblom, and M. Berg, "A novel method to model wheel-rail normal contact in vehicle dynamics simulation," Vehicle System Dynamics, vol. 52, no. 12, pp. 1752-1764, 2014.

[61] P. Weston, C. Ling, C. Goodman, C. Roberts, P. Li, and R. Goodall, "Monitoring lateral track irregularity from in-service railway vehicles," Proceedings of the Institution of Mechanical Engineers, Part F: Journal of Rail and Rapid Transit, vol. 221, no. 1, pp. 89-100, 2007.

[62] P. Weston, C. Roberts, G. Yeo, and E. Stewart, "Perspectives on railway track geometry condition monitoring from in-service railway vehicles," Vehicle System Dynamics, vol. 53, no. 7, pp. 1063-1091, 2015.

[63] B. Allotta, V. Colla, and M. Malvezzi, "Train position and speed estimation using wheel velocity measurements," Proceedings of the Institution of Mechanical Engineers, Part F: Journal of Rail and Rapid Transit, vol. 216, no. 3, pp. 207-225, 2002.

[64] Ö. Ararat and M. T. Söylemez, "Robust velocity estimation for railway vehicles," IFAC-PapersOnLine, vol. 50, no. 1, pp. 5961-5966, 2017.

[65] M. Spindler, D. Stein, and M. Lauer, "Low power and low cost sensor for train velocity estimation," in Intelligent Rail Transportation (ICIRT), 2016 IEEE International Conference on. IEEE, 2016, pp. 259-264.

[66] MATLAB, version 9.2.0.556344 (R2017a). Natick, Massachusetts: The MathWorks Inc., 2017.

[67] Y. Zhou, T. Mei, and S. Freear, "Real-time modeling of wheel-rail contact laws with system-on-chip," IEEE Transactions on Parallel and Distributed Systems, vol. 21, no. 5, pp. 672-684, 2010.

[68] P. Westeon, C. Ling, C. Roberts, C. Goodman, P. Li, and R. Goodall, "Monitoring vertical track irregularity from in-service railway vehicles," Proceedings of the institution of mechanical engineers, Part F: Journal of Rail and Rapid Transit, vol. 221, no. 1, pp. 75-88, 2007.

[69] E. Vollebregt, "Numerical modeling of measured railway creep versus creep-force curves with contact," Wear, vol. 314, no. 1-2, pp. 87-95, 2014.

[70] N. Wilson, R. Fries, M. Witte, A. Haigermoser, M. Wrang, J. Evans, and A. Orlova, "Assessment of safety against derailment using simulations and vehicle acceptance tests: a worldwide comparison of state-of-theart assessment methods," Vehicle System Dynamics, vol. 49, no. 7, pp. 1113-1157, 2011.

[71] A. Onat, "A novel and computationally efficient joint unscented kalman filtering scheme for parameter estimation of a class of nonlinear systems," IEEE Access, vol. 7, pp. $31634-31655,2019$.

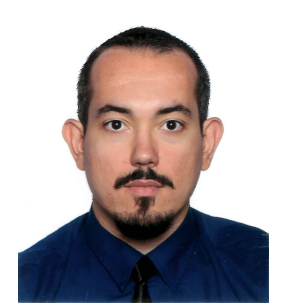

Altan Onat recevied his B.Sc. degrees in electricalelectronics and mechanical engineering from Eskisehir Osmangazi University, Turkey in 2009 and 2010, respectively. He received his M.Sc. degree in electrical-electronics engineering from Eskisehir Osmangazi University, Turkey in 2012 and his Ph.D. degree in transport means and diagnostics from University of Pardubice, Czechia in 2017. His research interests include condition monitoring, state and parameter estimation for railway vehicles, railway vehicle dynamics and control applications.

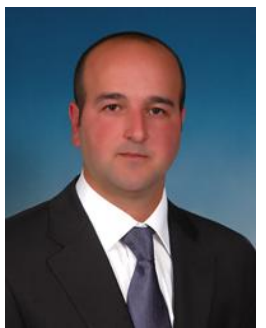

Bekir Tuna Kayaalp received his B.Sc. degree in civil engineering from Karadeniz Technical University, Turkey in 2011. He received his M.Sc. degree in transport engineering and communications in the field of transport means from University of Pardubice, Czechia in 2015 and he is currently a $\mathrm{PhD}$ candidate in the Faculty of Transport Engineering, University of Pardubice. His research interests include railway engineering, wheel-rail interaction and analyzing railway test equipments. 